Supplement of Geogr. Helv., 74, 13-25, 2019 https://doi.org/10.5194/gh-74-13-2019-supplement (C) Author(s) 2019. This work is distributed under the Creative Commons Attribution 4.0 License.

(c) (1)

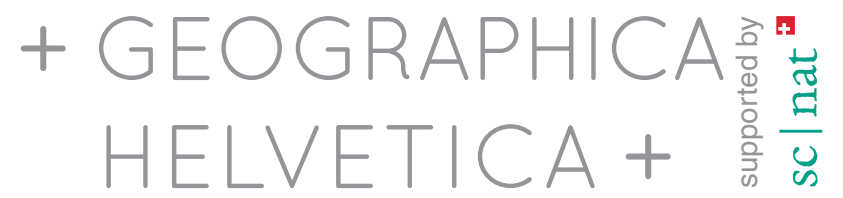

Supplement of

\title{
Territory, enclosure, and state territorial mode of production in the Russian imperial periphery
}

\section{Vera Smirnova}

Correspondence to: Vera Smirnova (veras@vt.edu)

The copyright of individual parts of the supplement might differ from the CC BY 4.0 License. 


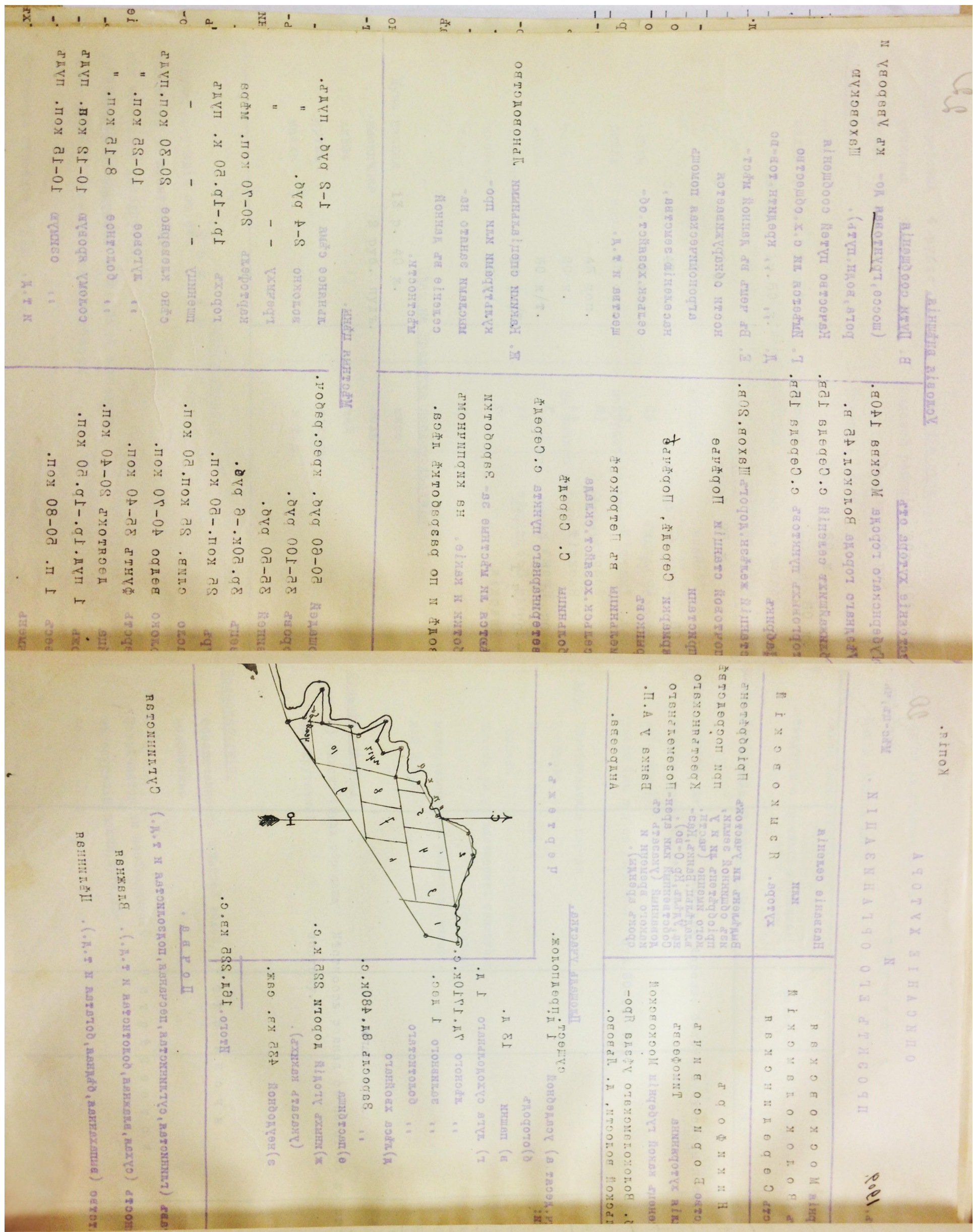




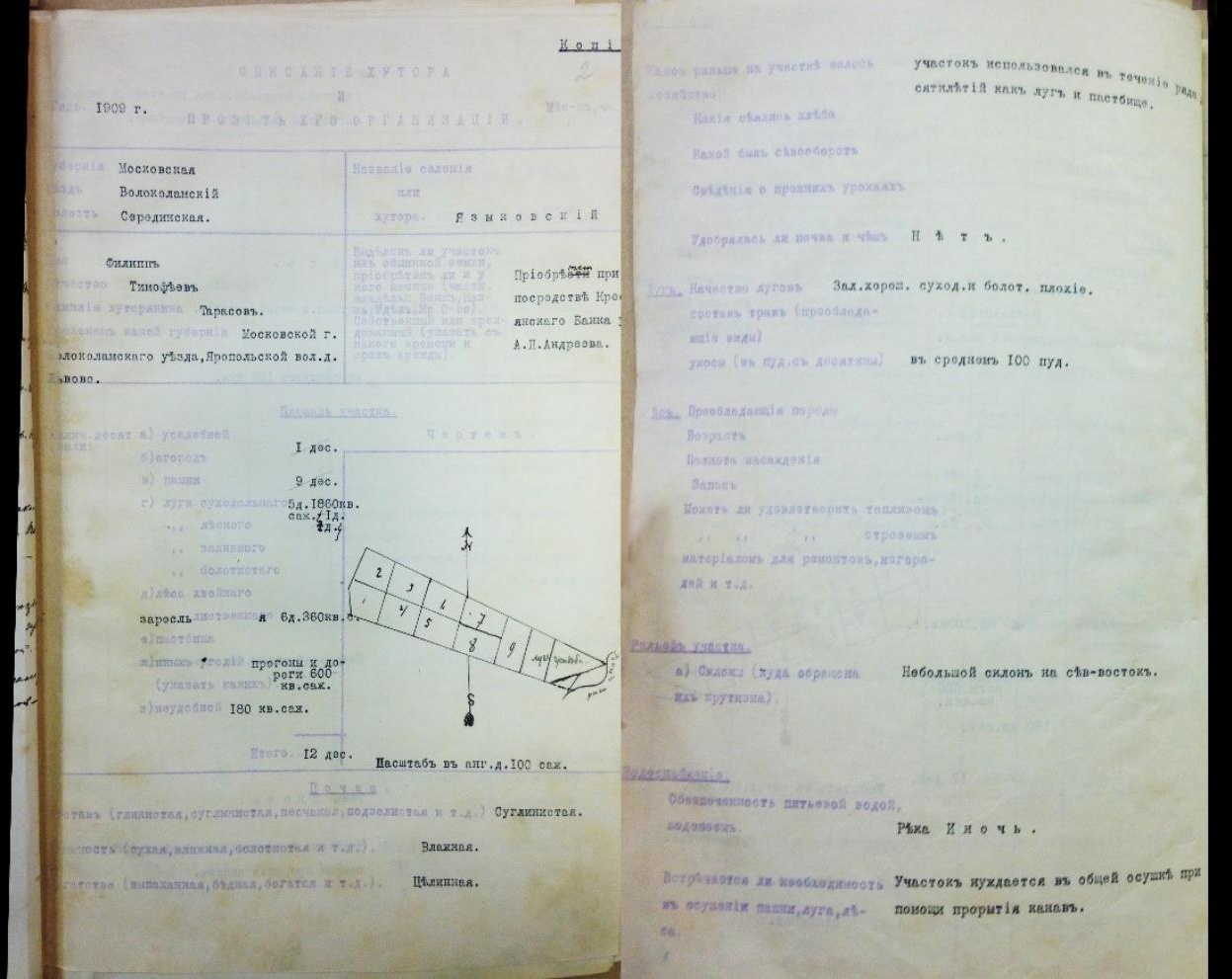




\section{ПОДВОРНОЕ НАДЬЛЕНІЕ.}

Распредъленіе земли деревни Ловмейки, Ковенской губерніи, ПоневБжскаго уБзда, Нацюнской волости, до разверстанія съ посторонними владьльцами.

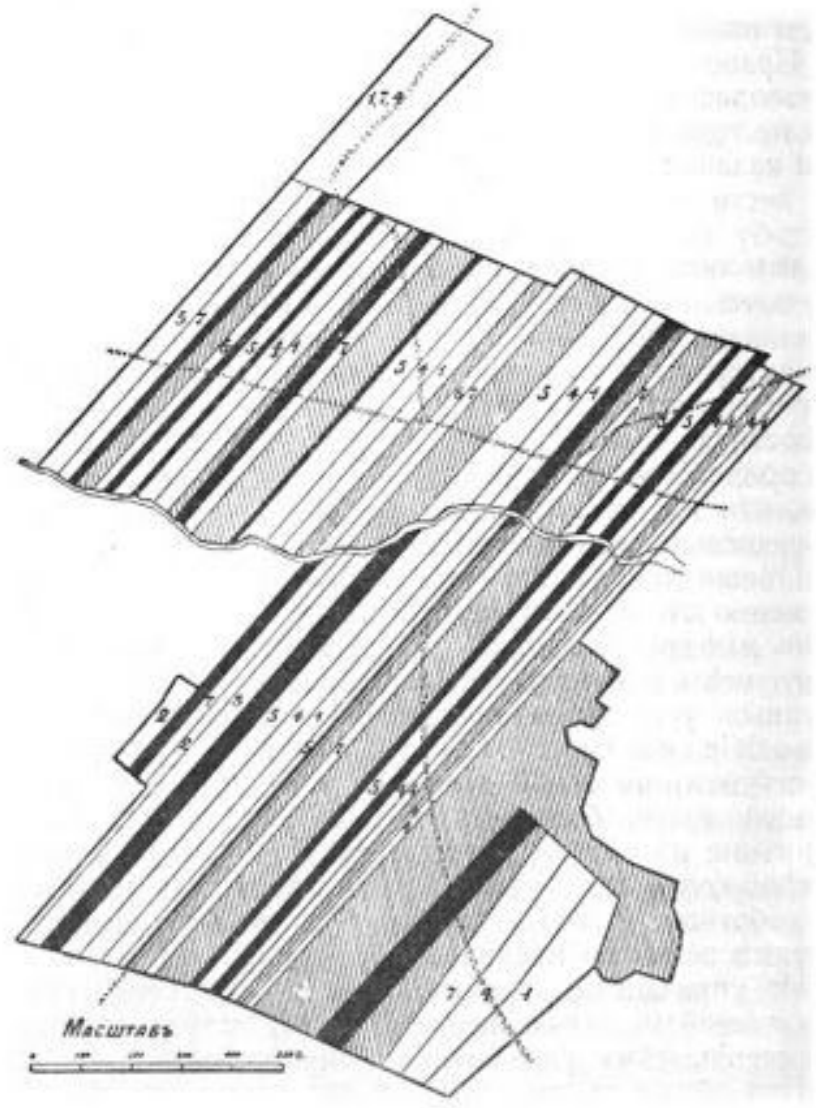

Пазнา. $\& 2$

\section{ПОДВОРНОЕ НАДБЛЕНІЕ.}

Распредьленіе земли деревни Ловмейки, Ковенской губерніи, Поневьжскаго уъзда, Нашюнской волости, посль разверстанія съ посторонними владђльшами и разбивки надъльной земли на хуторскіе участки.

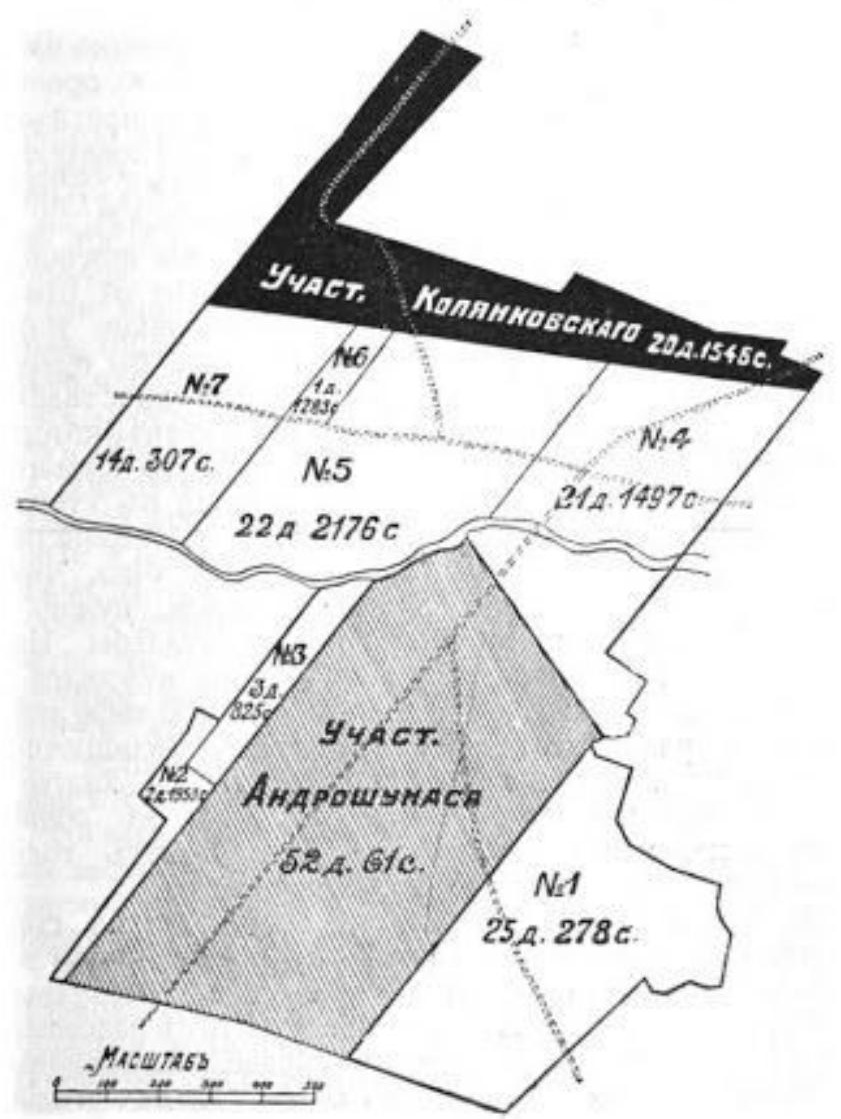




\section{ПОДВОРНОЕ НАДЬЛЕНІЕ.}

Распредьленіе земли деревни Гимбуие, Ковенской губерніи, Шавельскаго уьзда, Жагорской волости, до хуторского разселенія.

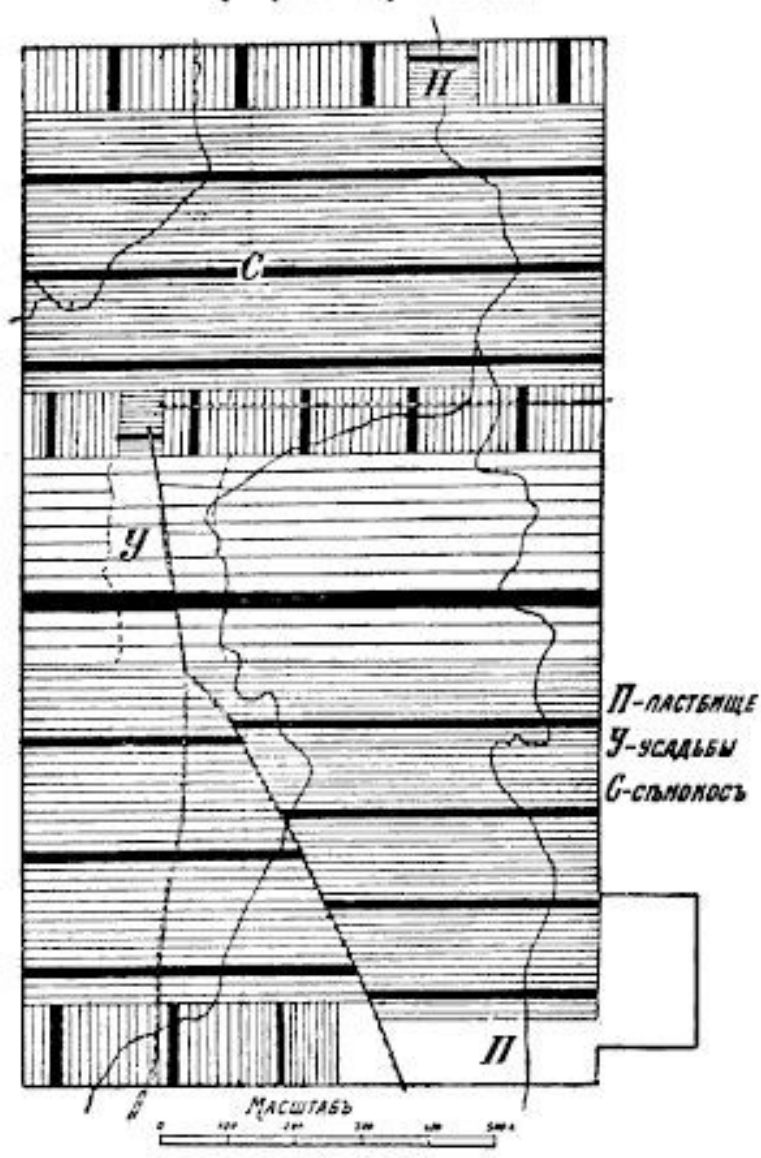

II gaito $\mathrm{N}$ ।I
Планъ хуторскихъ участковъ въ деревнь Гимбуце, Ковенской губерніи, Шавельскаго у ъзда, Жагорской волости. Надъленныхъ дворовъ-12. Наличныхъ дворовъ -16 .

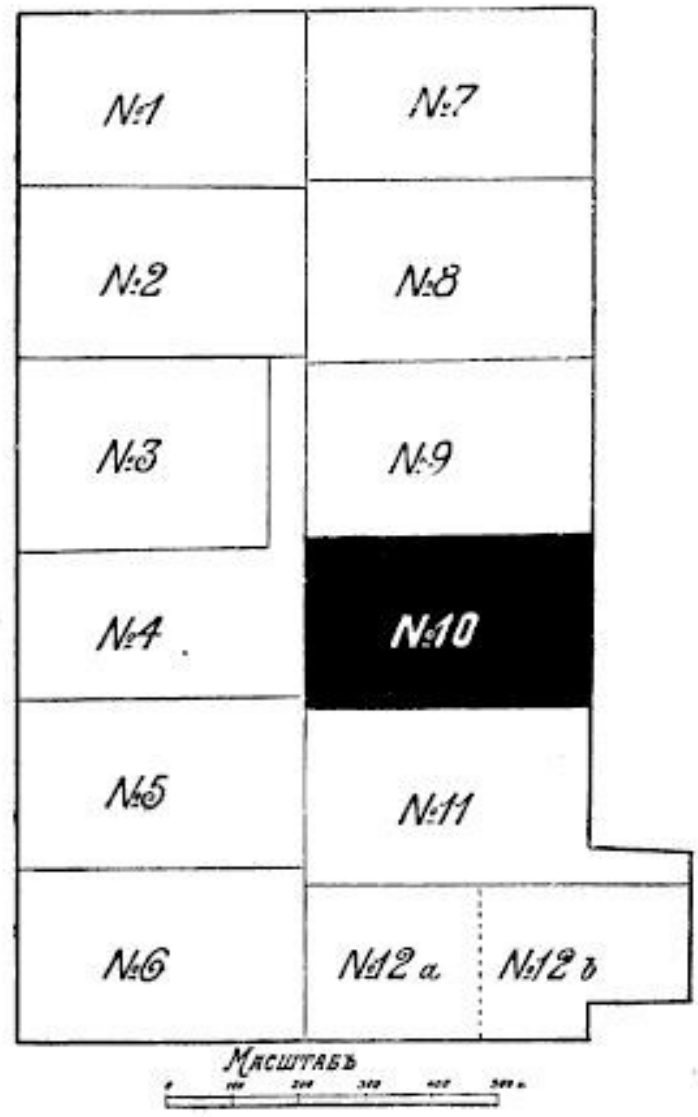

Планъ 스 12 